\title{
The impact of exercise of lower limbs on dynamic balance and valgus of the knees among young footballers
}

Bartosz Wilczyński ( $\nabla$ b.wilczynski.fizjoterapia@gmail.com )

Gdanski Uniwersytet Medyczny https://orcid.org/0000-0002-8663-3698

Katarzyna Zorena

Gdanski Uniwersytet Medyczny

Piotr Wąż

Gdanski Uniwersytet Medyczny

Research article

Keywords: video analyses, knee kinematics, dynamic knee valgus, signle leg squat, Y-Balance test, strenghtening programme

Posted Date: December 12th, 2019

DOI: https://doi.org/10.21203/rs.2.18619/v1

License: (1) This work is licensed under a Creative Commons Attribution 4.0 International License. Read Full License 


\section{Abstract}

Background Participation of children and youth in sporting activities, among others in training and football competitions, is an optimistic manifestation of activation in the current trend of computerization. Unfortunately, this is also often associated with musculoskeletal injuries. An example is the association of dynamic valgus and disturbed dynamic balance with lower limb injuries. The main purpose of the studies is to determine the impact of three strengthening exercises on the parameters of dynamic knee valgus and balance of lower limbs. The secondary objectives are to investigate the dominant influence and the length of lower limb on the valgus values and to determine risk of injury to young football players.

Methods 134 young footballers training at the Arka Gdynia SI club were invited to first stage of the research in order to examine anthropometric features and kinematics of the lower limb. Single Leg Squat Test was used, which was recorded. The samples were analyzed video to determine exact knee angle of valgus. During the second stage, to which players with valgus knee were qualified $\left(\geq 15^{\circ}\right)$, the Y-Balance Test was additionally used. Intervention group underwent an exercise program to strengthen gluteus medius, popliteal and tibialis posterior muscles for 6 weeks to repeat tests in the third stage.

Results Statistical methods used at the assumed level of significance allow to conclude that there are no differences in results of dynamic valgus $\left(\geq 15^{\circ}\right)$ and dynamic balance between the intervention group and control group during the 6 week period between stages. In addition, there were results confirming the lack of influence of length and dominant lower limb on valgus. Results of composite direction in the Y-Balance Test test determine the low risk of injury in both intervention and control groups.

Conclusions Intervention did not affect the dynamic valgus and knee balance in young football players. Both the length and the dominant limb did not affect the results. The "low risk" occurrence of injuries among the examined participants with valgus knee due to the values of dynamic balance was determined.

\section{Background}

Improving fitness, competition, pleasure, socialization, health are just a small part of the reasons why people around the world play football. Football training includes elements of medium and high intensity aerobic and anaerobic exercises with periods of anaerobic loads. Even a short-term period of a few to over a dozen weeks of recreational football training improves the values of the musculoskeletal, metabolic, cardiovascular systems, which has an obvious positive effect on health $[1,2]$.

However, due to due to high intensity of exercises, fatigue, frequent changes of running direction, accelerations, jumps, speed as well as impacts, contact with other players there is a risk of injury to the musculoskeletal system. This leads to the negative effects of individual players and the healthcare system, as demonstrated by the example of visits to emergency departments $[3,4]$.

Read et al. 2015 state that injuries of men playing football are found mainly in the lower limbs with a predominant non-contact incident and ligament injuries in the ankle and knee joint.

In addition, they distinguish the stages of adolescence and adolescence associated with injuries and loads with an emphasis on age from 9 to 15 [5].

Among the many factors that predispose injuries when training and participating in football matches, we should distinguish the mechanism of dynamic knee valgus and dynamic balance. Dynamic valgus of the knee joint may contribute to damage to the anterior cruciate ligament, medial collateral ligament, meniscus, cartilage, degenerative changes in the knee and pain in the patellofemoral joint [6-10]. By reducing the medial displacement of the knee, the risk of injury such as non-contact damage to the ACL ligament, pain in the patellofemoral joint and degeneration of articular cartilage is reduced $[11,12,8]$.

Participation in an exercise program aimed at preventing injuries is most beneficial for young people with low movement quality and high risk, therefore research should focus on young athletes with dynamic valgus observed, i.e. with an increased risk of injury [7]. 
The vast majority of programs focus on many often complex exercises not only strengthening but also stretching or equivalent [13-15]. The problem in implementing the home exercise plan that the participants report is the time they have to spend. It is also influenced by personal factors, daily variable and their interpretation as well as stress and negative mood on a given day. Clear and simple instructions regarding home recommendations are important $[16,17]$. The research results to date are divergent, which is why our goal was to find a simple intervention to improve the quality of movement among young football players.

The main purpose of our study was to determine the impact of the simple program with three exercises strengthening the gluteus medius, popliteal and tibialis posterior muscles, respectively, on dynamic valgus and dynamic balance of the lower limbs, and thus theassesment risk of injury for young footballers. The research hypothesis was based on the intervention chosen to increase the dynamic balance value and reduce the angulation of knee displacement in young players qualified in the screening test as knee valgus.In addition, we assumed the hypothesis that the asymmetry of the length of the lower limbs and the dominance of the limb affect the results of dynamic valgus.

\section{Methods}

\section{Patricipants}

One hunderd thirty four youngfootballers from 10 to 15 years old (mean: 12.5, SD: 1.7) who have been practicing football at the local club „Arka Gdynia Stowarzyszenie Inicjatywa” were invited.

Screening included composition analysis using the InBody 270 analyzer (InBody Co., Seoul, Korea) measuring body weight and BMI (Body Mass Index) and increase in height laser InKids (InBody Co., Seoul, Korea).

Information was collected from Author's questionnaire consisting of 4 questions, regarding the dominant leg, hours spent on physical activity during the week (divided into physical education classes, football training, motor training, other sports training, matches and / or sports events), injuries present, surgery in the last 2 years.The questionnaire was prepared in Polish and then translated into English for the needs of the manuscript.

Table 1. Characteristics of the study participants at the screening stage.

\begin{tabular}{|c|c|c|c|c|c|c|c|}
\hline Characteristics & $\mathrm{n}$ & $\min$ & $\max$ & median & p* & mean & sd \\
\hline Height (cm) & 134 & 132.5 & 188.1 & 155.5 & $<0.001$ & 158.77 & 14.38 \\
\hline Weight (kg) & 134 & 23.6 & 77.6 & 45.65 & $<0.001$ & 47.93 & 13.61 \\
\hline BMI $(\mathrm{kg} / \mathrm{m} \square)$ & 134 & 13.42 & 27.35 & 18.27 & 0.004 & 18.59 & 2.51 \\
\hline Skeletal muscle mass (kg) & 133 & 10.6 & 38.6 & 20 & 0.001 & 22.62 & 7.42 \\
\hline BMI (kg/m】) & 134 & 13.42 & 27.35 & 18.27 & 0.004 & 18.59 & 2.51 \\
\hline Football training (hours) & 130 & 0 & 16 & 6 & $<0.001$ & 5.92 & 2.11 \\
\hline Motor training (hours) & 130 & 0 & 5 & 1.25 & $<0.001$ & 1.40 & 0.70 \\
\hline Physical education classes (hours) & 130 & 0 & 10 & 4 & $<0.001$ & 3.85 & 2.02 \\
\hline Other sport activities (hours) & 130 & 0 & 10 & 1 & $<0.001$ & 1.05 & 1.42 \\
\hline Time spent on sports matches or tournaments & 134 & 1 & 12 & 5 & $<0.001$ & 4.99 & 1.93 \\
\hline
\end{tabular}

*p-value Shapiro - Wilk normality test 
sd - standard deviation

Participant get to know and agree with the information about the examination by the participant and the guardian / parent.

Participants were excluded from the study if they have not informed and written consent of the guardian/parent to participate in research, current tests of the sports medicine doctor, pain and/or injury during testing, surgical operations have been performed on the lower limbs and torso in the last 2 years.

Testing took place in Rehabilitation and Training Centre (Gdynia, Poland) between December 2018 and May 2019. The study was approved by the Independent Bioethical Committee for Scientific Research at the Gdańsk Medical University (resolution NKBBN / 567/2018).

\section{Design and Setting}

\section{First Stage}

After screening, 103 participants were qualified for the first stage of study. It included a one-leg squat test to examine the kinematics of the lower limb and to isolate people with dynamic valgus (criterium $\leq 15^{\circ}$ valgity of knee) subjects were disqualified due to unsuccessful attempts shown in the video analysis, of which 7 in 11 years old. Out of 88 correct samples, they were qualified as valgus of at least one lower limb in 52 people. They were invited to the second stage. 5 people could not attend the test sessions and 1 person gave up training in the club.

\section{Second Stage}

Before the start of the test session, a random randomization was performed for 46 qualified people. The intervention group (INT) consisted of 23 participants and a control group (CON) 23, but during the video anylyses 1 of participant was exluded from study due to invalid SLS test attempts. Using the Wilcoxon rank sum test it was shown that there is no statistically significant difference (at the assumed level of significance) in age and height between the CON group and the INT group.

The session consisted of two tests and a measure of the length of the lower limbs. Repeated use of one-leg squat test with re-application of rules and methodology from the first stage of research. The participants performed three repetitions this time for the left and right lower limbs, in order to more thoroughly investigate the dynamic distortion and verification of the screening test.

The second test was the Y-Balance Test to check the dynamic balance and neuromuscular control in determining the risk of lower limb injuries.

Within 6 weeks from the second stage tests, 3 participants were injured, one person gave up playing at the club, and one participant, by decision of the football coaches, was delegated to his home club, which resulted in exclusion from further research. 


\section{Third Stage}

The last, third stage of the research took place under the same conditions as the previous ones. It consisted of a repeated squat test in one of three trials for the left and right lower limbs and the Y-Balance Test. 40 competitors were invited again to the Rehabilitation and Training Center, of which 4 competitors did not show up in the dates selected by the researcher, 1 person was not tested with a single squat test for technical reasons and no data from the Y-Balance Test test was obtained in 1 person and was not taken for dynamic balance analysis.

Blinding the investigators was not feasible.

The collected data was used to analyze changes in group testing parameters over a period of 6 weeks.

\section{Testing Protocol}

\section{Single Leg Squat}

All attempts were carried out in a specially prepared place. Two GoProHero 4 digital video cameras (GoPro, Inc., San Mateo, USA) located on tripods, the first at a distance of $2 \mathrm{~m}$ laterally and the second at the front $1 \mathrm{~m}$ at the knee joint level of the subject. Both registered the pattern of the squat. Markers in the form of square kinesiotape patches were affixed in the anatomical points below the upper anterior iliac spine, at the middle point of the patella, and to the point of the ankle between the lateral and medial bones [18]. Before starting the test, all subjects watched the instructional video projected on the projector and were trained verbal information together with the demonstration of correct squat performance from the lateral perspective, so that they did not suggest the knee's anatomy from the frontal plane and could observe the minimum squat depth, i.e. min. $60^{\circ}$. Participants after the instruction were able to practice a given movement pattern until they were ready to take the test. Patients were instructed to stand barefoot on a line formed of two white patches to standardize the test site. Then, during the verbal signal of the researcher, the untested limb was bent to an angle of about $90^{\circ}$, the hip and knee of the limb tested straightened, the hands stacked crossed on the shoulders and the eyes are facing forward. Another signal from the researcher suggested starting the test. At the end, the subject returned to the starting position. The maximum duration of the squat for one lower limb was set as 5 seconds. Participants received information about the depth of the squat to be free and individual to perform the test.

One attempt was made for the left and right lower limbs. If the subject shifted his foot, heeled the heel, touched the ground with the limb, lost his balance, the test was considered unsuccessful and the test had to be repeated.

The researcher also visually analyzed the bending angle of the knee, if he felt that he was not deep enough, the test was repeated [18-21].

\section{Video analysis}


Next, the researcher made a video analysis of the oblique angles and/or deformation of the knee joint in the frontal plane and the angle of bending the knee joint in the sagittal plane. Free and freely available traffic tracking software was used with the Kinovea ${ }^{\circledR}$ (beta-version 0.8.26, Bordeaux, France) protractor tool [22].

Markers adhered to the previously mentioned anatomical areas of the participants were points determining the axis of the lower limbs.

On the video in the front projection, the researcher marked the middle of the patella in the center, followed by the upper anterior iliac spineand middle point between the lateral and medial ankle bones. The lateral projection was analyzed to determine the maximum angle of knee bending (at least $60^{\circ}$ for a successful sample) and included anatomical points without markers: greater trochanter, lateral condyle of the tibia and lateral ankle bone. The exit angle of the test limb was determined at the moment of tearing off the foot untested from the surface, the maximum angle of distortion or deformity was marked during the squat at the maximum deviation from the starting position. All angles were visually determined frame by frame. The subject was qualified as valgus if in the squat test she obtained an angle $\leq 15^{\circ}$ from the exit angle. The deforming person had to get an angle of $\geq 15^{\circ}$ from the exit angle. Knee alignment in the range of $14^{\circ}-0^{\circ}-14^{\circ}$ was recorded as a normal limb. If, during the video analysis, the researcher noticed the irregularities in the test performance, he classified it as an unsuccessful attempt, without the possibility of repetition. Combining all stages of the research, the analysis was subjected to 368 video from the front and side projection.

\section{Y-Balance Test}

The test consists in keeping the standing position one-legged with the hands placed at the hips on the leg placed on the stand arranged so that the big finger touches the horizontal line [23]. With a free limb, the participant moves the block towards the anterior, posterolateral and hindlimbal way, trying to get the most distant point, and then return to the starting position [24-26]. The study was carried out with recommendations for standardization of the protocol according to Plisky et al 2008, i.e .: (participants performed the test without shoes, 6 trial leg tests for all directions to minimize the learning effect., video instruction on how to perform the test, standardized testing order to avoid fatigue. Participants changed limbs for each direction alternately, starting point of the laden load in the same position, permitted foot movements, ie heel or forefoot separation, any body movement is allowed, normalization to the length of the lower limb, same platform height [27].

The length of the lower limbs was measured on the therapy table. The researcher straightened his legs to align the pelvis. The length was measured from the upper anterior iliac spineto the medial ankle of the lower limb.

The subjects performed 3 repetitions of the left and right lower limbs in 3 directions. The test was considered unsuccessful at the moment when the person lost balance, did not return to the starting position, bounced off the platform or lost contact with her in an uncontrolled manner, the loaded foot moved to the horizontal line. The 
distance of the offset platform was registered as the result of a given limb for a specific direction with an accuracy of $1 \mathrm{~cm}$. Range was normalized with the length of the limbs [24, 26].

\section{Intervention Program}

The intervention group held a 6-week exercise program, 3 times a week independently at home and once per motor training under the control of physiotherapists. The control group did not perform exercises. Both groups participated without interruption in their sports activities. The program consisted of three resistance exercises using elastic rehabilitation tape. Exercises strengthening of the gluteus medius, popliteal and tibialis posterior muscles. These muscles affect the movements in the hip, knee and ankle joints, respectively. Isolated muscle strengthening exercises are based on the guidelines of the National Health of Sport Medicine on a combination of concentric contractions - 1 second, isometric - 2 seconds and eccentric - 4 seconds in order to activate the muscle in the best possible way. Exercises were performed for the left and right lower limbs [28].

The tape was selected to the age of the participant. The respondents from the years 11-13 received a blue tape with a thickness of $0.50 \mathrm{~mm}$, and the subjects $14-16$ received a black tape with a higher resistance of $0.65 \mathrm{~mm}$.

In addition, the participants received a package with information for the guardian/parent regarding motivational support and involvement in the exercises of the young athlete, illustrations with a detailed description of the exercises (attachment), a card with a specially generated website address to the base in which instructional videos about the exercise were posted and the method of tying the tape.

The package also included a calendar with information on the progression of the weekly program. The task of the respondents was to mark the training days in the training diary as a verification of the exercise of home exercises.

Table 2. Description of the exercises performed during the training sessions.

\begin{tabular}{|c|c|c|c|c|}
\hline Execution & Exercise & Week 1 & Week 2-3 & Week 4-6 \\
\hline Contraction: & Gluteus medius & $\begin{array}{c}2 \text { sets } 10 \\
\text { reps }\end{array}$ & $\begin{array}{c}3 \text { sets } 10 \\
\text { reps }\end{array}$ & $\begin{array}{l}3 \text { sets } 15 \\
\text { reps }\end{array}$ \\
\hline $\begin{array}{l}\text { concentric }-1 \mathrm{sec} \\
\text { izometric - } 2 \mathrm{sec}\end{array}$ & Popliteus [ & $\begin{array}{c}2 \text { sets } 10 \\
\text { reps }\end{array}$ & $\begin{array}{c}3 \text { sets } 10 \\
\text { reps }\end{array}$ & $\begin{array}{l}3 \text { sets } 15 \\
\text { reps }\end{array}$ \\
\hline eccentric - 4sec & Tibialis posterior & $\begin{array}{c}2 \text { sets } 10 \\
\text { reps }\end{array}$ & $\begin{array}{c}3 \text { sets } 10 \\
\text { reps }\end{array}$ & $\begin{array}{l}3 \text { sets } 15 \\
\text { reps }\end{array}$ \\
\hline
\end{tabular}

¿Gluteus medius: Starting position: lying sideways, unprocessed leg bent in the knee joint, exercised leg straightened. The arm on the side of the exercised leg lies on the hip. Tape tied over the patella.

Exercise: raising the straight leg to an angle of about 30 degrees in the hip joint. 
$\square$ Popliteus: Starting position: Standing on one leg. Hands resting on hips. Tape applied to the forefoot of the free limb.

Exercise: Flexion movement in the knee joint with simultaneous external rotation of the thigh and internal rotation of the shin.

aTibialis posterior:Starting position: sitting position with bent knees around $80^{\circ}$, the forearm on the side of the exercised leg based on the knee for stability. The foot is in contact with the ground. Tape hooked at the forefoot and directed at an angle of $45^{\circ}$

Exercise: Foot adduction (Internal rotation of the shin without femur movement).

\section{Statistical Analyses}

The statistical analysis was performed using R statistics langua. The Shapiro-Wilk test was used to determine if the values are of the normal distribution. Depending on the obtained p-values from the above-mentioned test, the student's t-test or the Wilcoxon rank sum test were used to compare two groups of the quantitative variables. For a comparison of more than two groups of quantitative variables, a one-way ANOVA, Friedman or Kruskal-Wallis test were used. For qualitative variables, Fisher's test was used to determine independence from selected variables. Correlations in three available variants were also calculated for selected quantitative variables.

The level of statistical significance was the threshold of $\alpha=0.05$.

\section{Results}

\section{Dynamic knee valgus}

As shown in Table 3 after completing the exercise program, the left valgus angle of exercise group decreased by 2.6 $6^{\circ}$. The analysis using Friedman and ANOVA test showed no statistically significant differences between the CON group and the INT group.

Table 3. Analysis of mean of 3 SLS tests between Pre-training and Post-training stage in the intervention and control group for the left and right limbs. 


\begin{tabular}{c|c|c|c|}
\hline \multicolumn{2}{|c|}{} & Pre-training & Post-training \\
\hline \multirow{2}{*}{ Group } & Lower Limb & \multicolumn{2}{|c|}{$\begin{array}{r}\text { Valgus angle } \\
\text { mean } \pm \text { sd }\end{array}$} \\
\hline \multirow{2}{*}{ Intervention } & Left & $16.1 \pm 10.5 \square$ & $13.5 \pm 8.8 \square$ \\
\cline { 2 - 4 } & Right & $16.3 \pm 11.8 \square$ & $16.9 \pm 11.7 \square$ \\
\hline \multirow{2}{*}{ Control } & Left & $18 \pm 9.7 \square$ & $17.7 \pm 12.6 \square$ \\
\cline { 2 - 4 } & Right & $18.5 \pm 12 \square$ & $18.8 \pm 12.1 \square$ \\
\hline
\end{tabular}

घINT Pre-traing $(\mathrm{n}=22)$

aINT Post-traing $(n=17)$

口CON Post-training $(\mathrm{n}=18)$

๑CON Pre-training $(\mathrm{n}=23)$

\begin{tabular}{|c|c|c|c|c|}
\hline Attempts & Stage & Group & Variable & p* \\
\hline \multirow[t]{4}{*}{$1,2,3$} & \multirow[t]{4}{*}{ PRE and POST } & \multirow[t]{2}{*}{ Control } & Right valgus knee & $0.926 \square$ \\
\hline & & & Left valgus knee & 0.539 \\
\hline & & \multirow[t]{2}{*}{ Intervention } & Right valgus knee & $0.844 \square$ \\
\hline & & & Left valgus knee & $0.540 \square$ \\
\hline
\end{tabular}

* p-value

๑ Friedman rank sum test

५ ANOVA test

Determination of independence from traits, i.e. lower left and right limbs, and determination of belonging to the control and intervention groups was obtained using Fisher's Exact Test for count data. In both stages of research, in each case the result is not statistically significant. The valgus in each trial does not depend on the selected features.

Table 4. Determination of independence from traits and group membership at pr-training and post-training stage. 


\begin{tabular}{|c|c|c|c|c|c|c|c|}
\hline \multirow[b]{2}{*}{ iLS/Dynamic valgus } & \multirow[b]{2}{*}{ Group } & \multicolumn{3}{|c|}{ Pre-Training } & \multicolumn{3}{|c|}{ Post-Training } \\
\hline & & Left valgus & Right valgus & $\mathrm{p} *$ & Left valgus & Right valgus & $p^{*}$ \\
\hline \multirow[t]{2}{*}{ Attempt 1} & INT & 13 & 13 & \multirow[t]{2}{*}{1} & 7 & 10 & \multirow[t]{2}{*}{0.743} \\
\hline & $\mathrm{CON}$ & 16 & 14 & & 10 & 10 & \\
\hline \multirow[t]{2}{*}{ Attempt 2} & INT & 13 & 10 & \multirow[t]{2}{*}{0.788} & 9 & 10 & \multirow[t]{2}{*}{1} \\
\hline & $\mathrm{CON}$ & 17 & 17 & & 10 & 11 & \\
\hline \multirow[t]{2}{*}{ Attempt 3} & INT & 11 & 10 & \multirow[t]{2}{*}{1} & 8 & 10 & \multirow[t]{2}{*}{1} \\
\hline & $\mathrm{CON}$ & 14 & 13 & & 11 & 12 & \\
\hline
\end{tabular}

* p-value - Fisher's Exact Test for count data

\section{Lower limb dominance}

The choice of control and intervention groups due to the dominant leg is not statistically significant. Left dominant (INT - 2, CON - 4), Right dominant (INT - 20, CON - 19).

Determining the difference due to the dominant leg was also examined by Fisher's test. The choice of CON and INT group due to the dominant leg is not statistically significant $\mathrm{p}=0.665$.

The Wilcoxon rank sum test was used to determine the effect of the dominant lower limb on dynamic valgus values. Each trial was tested for the left and right legs.

All results are not statistically significant. There are no differences between valgus values due to the dominant leg (Table 5).

Table 5. The effect of the dominant lower limb on dynamic valgus values.

\begin{tabular}{c|c|c|}
\hline SLS - Dynamic valgus & Attempt & $\mathbf{p} *$ \\
\hline left lower limb & 1 & 0.758 \\
\cline { 2 - 3 } & 2 & 0.693 \\
\cline { 2 - 3 } & 3 & 0.320 \\
\hline right lower limb & 1 & 0.595 \\
\cline { 2 - 3 } & 2 & 0.945 \\
\cline { 2 - 3 } & 3 & 0.797 \\
\hline
\end{tabular}

* p-value Wilcoxon rank sum test

\section{Lower limb length}

Values describing valgus for the right and the left legs have been collected. Three measurements have been performed for each leg. The measured valgus values for each leg have been split into three groups in subsequent measurements. Participants with a longer right leg, participants with a longer left leg, and participants with the right and the left leg of the same length, belong to the first, the second, and the third group respectively. The three groups have been examined using the Kruskal-Wallis test. The p-values for the first 
measurement are 0.6655 and 0.7881 for the right and left leg, respectively. The p-values for the second measurement are 0.2404 and 0.8025 for the right and left leg, respectively. The p-values for the third measurement are 0.2332 and 0.3579 for the right and left leg, respectively. The results are not statistically significant in all the cases.

\section{Dynamic balance}

In the next step of the analysis, the t-student test (taking into account the results of the analysis of the variance) and the Wilcoxon rank sum test, were used. Using these tests, the differences between the control group and the intervention group were examined for values describing the so-called dynamic balance. The calculations have been performed separately for step II (pre-training) and step III (post-training). The obtained p-values between the control and intervention groups for the above-mentioned tests at each step exclude the existence of a statistically significant difference (Fig. 4, Fig. 5).

Determination of the occurrence of differences between the average of 3 attempts from PRE-training stage and the average of 3 attempts from POST-training stage inside the CON and INT group was determined by analysis with the ANOVA test for normal distribution sets and Friedman test for non-normal distribution sets.

There were statistically significant differences between the means of three attempts of the pre training and the post-training stage both in the CON and the INT group. The values differed in INT group for the right lower limb in all directions of Y-Balance Test ANT- anterior, PM - posteromedial, PL - posterolateral, (ANT, p = 0.009, PM, $\mathrm{p}=0.033, \mathrm{PL}, \mathrm{p}=0.011)$ and for the left limb in the PL $(\mathrm{p}=0.029)$. In CON group only for right lower limb ANT $(\mathrm{p}=0.00002)$ and $\mathrm{PM}(\mathrm{p}=0.026)$.

For the next step of the analysis of variance, multiple comparisons were used - Friedman's post-hoc test to check which variables are different. Statistically significant differences occurred mainly between trials 3 or 2 vs 1 , mostly at the POST vs PRE stages (Table 5).

Table 5. Comparison of post-hoc tests of Y-Balance Test control and intervention groups at both stages. 


\begin{tabular}{|c|c|c|}
\hline \multicolumn{3}{|c|}{ CONTROL GROUP - RIGHT LOWER LIMB - ANTERIOR } \\
\hline STAGE & ATTEMPTS & p-value \\
\hline POST - PRE & $2-1$ & 0.033 \\
\hline PRE - PRE & $3-1$ & 0.00002 \\
\hline POST - PRE & $3-1$ & 0.0007 \\
\hline PRE - POST & $3-1$ & 0.029 \\
\hline \multicolumn{3}{|c|}{ CONTROL GROUP - RIGHT LOWER LIMB - POSTERIORMEDIAL } \\
\hline POST - PRE & $3-1$ & 0.013 \\
\hline \multicolumn{3}{|c|}{ INTERVENTRION GROUP - RIGHT LOWER LIMB - ANTERIOR } \\
\hline \multirow[t]{2}{*}{ POST - PRE } & $2-1$ & 0.040 \\
\hline & $3-1$ & 0.009 \\
\hline \multicolumn{3}{|c|}{ INTERVENTRION GROUP - RIGHT LOWER LIMB - POSTERIORLATERAI } \\
\hline POST - PRE & $3-1$ & 0.005 \\
\hline \multicolumn{3}{|c|}{ INTERVENTRION GROUP - RIGHT LOWER LIMB - POSTERIORMEDIAL } \\
\hline POST - PRE & $3-1$ & 0.037 \\
\hline \multicolumn{3}{|c|}{ INTERVENTRION GROUP - LEFT LOWER LIMB - POSTERIORLATERAL } \\
\hline POST - PRE & $2-1$ & 0.008 \\
\hline
\end{tabular}

Correlation between dynamic valgus and the dynamic balance in young footballers.

Correlations between dynamic valgus (SLS test) and the dynamic balance (YBT) were determined using Kendall's, Spearman's and Pearson's correlation coefficients. There was significant inverse correlation mostly between attempts of YBT in ANT direction and attempts of SLS mostly in CON group for both legs in young footballers.

Table 6. Correlation results between SLS and Y-Balance Test between control and intervention group at both stages. Statistically significant results. 


\begin{tabular}{|c|c|c|c|c|c|c|c|c|c|}
\hline $\begin{array}{l}\text { Y-Balance } \\
\text { Test } \\
\text { (direction, } \\
\text { leg,attempt, } \\
\text { stage) }\end{array}$ & $\begin{array}{l}\text { SLS - } \\
\text { dynamic } \\
\text { valgus } \\
\text { (leg, } \\
\text { attempt, } \\
\text { stage) }\end{array}$ & $\begin{array}{l}\tau, \\
\text { Kendall }\end{array}$ & $\begin{array}{l}\rho, \\
\text { Spearman }\end{array}$ & $\begin{array}{l}\text { r, } \\
\text { Pearson }\end{array}$ & $\begin{array}{l}\text { Y-Balance } \\
\text { Test } \\
\text { (direction, } \\
\text { leg,attempt, } \\
\text { stage) }\end{array}$ & $\begin{array}{l}\text { SLS - } \\
\text { dynamic } \\
\text { valgus } \\
\text { (leg, } \\
\text { attempt, } \\
\text { stage) }\end{array}$ & $\begin{array}{l}\tau, \\
\text { Kendall }\end{array}$ & $\begin{array}{l}\rho, \\
\text { Spearman }\end{array}$ & $\begin{array}{l}r, \\
\text { Pearson }\end{array}$ \\
\hline \multicolumn{5}{|c|}{ CON GROUP LEFT LEG } & \multicolumn{5}{|c|}{ CON GROUP RIGHT LEG } \\
\hline ANT-1-PRE & 1-POST & -0.57 & -0.70 & $\begin{array}{c}-0.74 \\
- \\
\end{array}$ & ANT-1-PRE & 1-POST & $\begin{array}{c}\underline{-0.36} \\
- \\
\end{array}$ & $\begin{array}{c}-0.50 \\
- \\
\end{array}$ & $\begin{array}{c}-0.48 \\
- \\
\end{array}$ \\
\hline ANT-1-PRE & 2-POST & $\frac{-0.40}{-}$ & $\frac{-0.49}{-}$ & $\underline{-0.58}$ & $\begin{array}{l}\text { ANT-1- } \\
\text { POST }\end{array}$ & 1-PRE & -0.32 & $\underline{-0.48}$ & -0.39 \\
\hline ANT-1-PRE & 3-POST & $\begin{array}{c}-0.56 \\
- \\
\end{array}$ & $\begin{array}{c}-0.71 \\
- \\
\end{array}$ & $\begin{array}{c}-0.74 \\
- \\
\end{array}$ & ANT-2-PRE & 1-POST & -0.33 & $\begin{array}{c}-0.36 \\
-\end{array}$ & $\begin{array}{c}-0.52 \\
-\end{array}$ \\
\hline ANT-2-PRE & 1-POST & $\begin{array}{c}-0.39 \\
- \\
\end{array}$ & $\begin{array}{c}-0.52 \\
- \\
\end{array}$ & $\begin{array}{c}-0.61 \\
- \\
\end{array}$ & ANT-2-PRE & 1-PRE & $\begin{array}{c}-0.39 \\
- \\
-\end{array}$ & $\begin{array}{c}-0.50 \\
- \\
\end{array}$ & - \\
\hline ANT-2-PRE & 2-POST & -0.26 & -0.35 & $\begin{array}{c}-0.53 \\
- \\
\end{array}$ & $\begin{array}{l}\text { ANT-2- } \\
\text { POST }\end{array}$ & 1-POST & - & $\begin{array}{c}-0.36 \\
- \\
\end{array}$ & $\begin{array}{c}-0.51 \\
- \\
\end{array}$ \\
\hline ANT-2-PRE & 3-POST & -0.32 & -0.41 & $\begin{array}{c}-0.53 \\
- \\
\end{array}$ & $\begin{array}{l}\text { ANT-2- } \\
\text { POST }\end{array}$ & 2-POST & $\begin{array}{c}-0.40 \\
- \\
\end{array}$ & $\begin{array}{c}-0.55 \\
- \\
\end{array}$ & $\begin{array}{c}-0.50 \\
- \\
\end{array}$ \\
\hline $\begin{array}{l}\text { ANT-2- } \\
\text { POST }\end{array}$ & 1-PRE & -0.28 & -0.42 & $\underline{-0.49}$ & ANT-3-PRE & 1-PRE & $\frac{-0.33}{-}$ & $\frac{-0.46}{-}$ & - \\
\hline $\begin{array}{l}\text { ANT-2- } \\
\text { POST }\end{array}$ & 2-PRE & -0.29 & -0.40 & $\begin{array}{c}-0.54 \\
- \\
\end{array}$ & $\begin{array}{l}\text { ANT-3- } \\
\text { POST }\end{array}$ & 2-PRE & $\begin{array}{c}-0.51 \\
-\end{array}$ & $\begin{array}{c}-0.69 \\
- \\
\end{array}$ & - \\
\hline $\begin{array}{l}\text { ANT-2- } \\
\text { POST }\end{array}$ & 2-POST & -0.30 & -0.46 & $\begin{array}{c}-0.51 \\
- \\
\end{array}$ & $\begin{array}{l}\text { ANT-3- } \\
\text { POST }\end{array}$ & 1-POST & $\begin{array}{c}-0.44 \\
- \\
\end{array}$ & $\begin{array}{c}-0.59 \\
- \\
\end{array}$ & $\begin{array}{c}-0.60 \\
- \\
\end{array}$ \\
\hline $\begin{array}{l}\text { ANT-2- } \\
\text { POST }\end{array}$ & 3-POST & $\begin{array}{c}-0.45 \\
- \\
\end{array}$ & $\begin{array}{c}-0.60 \\
- \\
\end{array}$ & $\begin{array}{c}-0.63 \\
- \\
\end{array}$ & $\begin{array}{l}\text { ANT-3- } \\
\text { POST }\end{array}$ & 3-POST & $\begin{array}{c}\underline{-0.43} \\
- \\
\end{array}$ & $\begin{array}{c}-0.55 \\
- \\
\end{array}$ & - \\
\hline $\begin{array}{l}\text { ANT-3- } \\
\text { POST }\end{array}$ & 2-PRE & -0.33 & -0.44 & -0.61 & PL-1-POST & 2-POST & -0.40 & $\underline{-0.53}$ & -0.48 \\
\hline $\begin{array}{l}\text { ANT-3- } \\
\text { POST }\end{array}$ & 3-PRE & -0.32 & -0.41 & $\begin{array}{c}-0.47 \\
- \\
\end{array}$ & PM-1-PRE & 2-POST & $\begin{array}{c}-0.41 \\
- \\
\end{array}$ & $\begin{array}{c}-0.51 \\
- \\
\end{array}$ & - \\
\hline $\begin{array}{l}\text { ANT-3- } \\
\text { POST }\end{array}$ & 1-POST & $\begin{array}{c}-0.36 \\
- \\
\end{array}$ & -0.44 & $\begin{array}{c}-0.53 \\
- \\
\end{array}$ & - & - & - & & \\
\hline $\begin{array}{l}\text { ANT-3- } \\
\text { POST }\end{array}$ & 3-POST & $\begin{array}{c}-0.37 \\
- \\
\end{array}$ & $\begin{array}{c}-0.51 \\
- \\
\end{array}$ & $\begin{array}{c}-0.60 \\
- \\
\end{array}$ & - & - & - & & \\
\hline PL-3-POST & 1-PRE & $\underline{-0.34}$ & -0.43 & -0.37 & & & & & \\
\hline
\end{tabular}




\begin{tabular}{c|c|c|c|c|c|c|c|c|c|} 
PL-3-POST & 3-PRE & -0.40 & $\underline{-0.55}$ & $\underline{-0.54}$ & - & - & - & \\
\hline PM-2-POST & 3-PRE & -0.27 & -0.33 & $\underline{-0.48}$ & - & - & - & \\
\hline \\
\hline PM-1-PRE & 1-PRE & $\underline{-0.33}$ & $\underline{-0.49}$ & -0.39 & ANT-2-PRE & 2-POST & $\underline{-0.39}$ & $\underline{-0.50}$ & - \\
\hline PM-3-PRE & 1-PRE & $\underline{-0.36}$ & $\underline{-0.50}$ & $\underline{-0.54}$ & - & - & - & & - \\
\hline ANT-2-POST & 2-PRE & $\underline{-0.52}$ & $\underline{-0.69}$ & - & - & - & & & \\
\hline
\end{tabular}

\section{Legend:}

Direction of YBT - ANT - anterior, PL - posterolateral, PM - posteromedial.

PRE - pre-training stage, POST - post-training stage

1-2-3 - number of attempts

Bolds and highlighted - statically significant

\section{Discussion}

\section{Dynamic knee valgus}

This study showed that the proposed exercises to strengthen the muscles of the lower limb in young football players do not significantly affect dynamic valgus by reducing the valgus angle measured in the frontal plane. But, after a 6-week exercise program, the left limb valgus angle for the intervention group decreased by $2.6^{\circ}$, however, this result is not clinically relevant.

Palmer et al. 2015 and Patrek et al. 2011 research focusing on valgus 3D assessment determined a $3^{\circ}$ positive change as clinically significant and representative. The researchers used a one-leg landing test to assess, which due to a similar motion pattern can be compared to a one-leg squat test in the context of valgus assessment $[14,30]$.

In addition, Palmer et al. 2015, using the hip abduction exercise strengthening the gluteal muscles over a 6 week period in military personnel, showed a high tendency to decrease valgus by $5^{\circ}$ defined as clinically significant, but not statistically significant. Intervention group performed exercises focused on strengthening hip abductors [14].

Video analysis showed mean of knee valgus angle at the pre-training stage for the left leg CON group $\left(18^{\circ} \pm 9.7^{\circ}\right)$, INT $\left(16.1^{\circ} \pm 10.5\right.$ $\left.{ }^{\circ}\right)$ and for right leg CON $\left(18.5^{\circ} \pm 12.0^{\circ}\right)$, INT $\left(1.3^{\circ} \pm 11.8^{\circ}\right)$.

The results can be described as 'poor' by referring to the study by Räisänen et al. 2015, in which such an assessment was attributed to $19^{\circ}$ and $18^{\circ}$ for the dominant and non-dominant legs [31].

In further studies of knee valgus, Räisänen et al. 2015 again published a study that identified athletes with a high angle (1sd above the mean $>23.8^{\circ}$ ) of knee valgus in the frontal plane as 2.7 times more likely to have lower extermity injuries.

The team described the results thatdynamic knee valgity measured during SLS is not by itself sufficient screening tool for the risk of injuries in future [32]. 
The results of dynamic valgus $\left(\geq 15^{\circ}\right)$ did not differ statistically from both groups irrespective of whether the participant had a left or right limb in all 3 trials of the SLS in both the pre-training and post-training test stages. These results allow the conclusion that there is no significant effect of valgus asymmetry on the results.

Participants defined the dominant lower limb as left $(n=6)$ and right $(n=39)$. The dominant leg did not affect the results of dynamic valgus.

In addition, lower limb lenght did not affect dynamic knee valgus results. Regardless of whether the participant's left or right long limb or both are identical.Both results reject the hypothesis.

\section{Dynamic balance}

The differences between the intervention and the control group during the 6-week period between the stages were not statistically significant. This result rejects the hypothesis that the intervention group will obtain higher values than the control group among football players with knee valgus displacement.

There were changes between the average of 3 trials of the PRE and the POST training stage in both groups. The values differed for the right lower limb in all directions and for the left limb in the posterolateral direction. These differences are significantly statistical.

An interesting phenomenon studied is the differences obtained through the use of post-hoc analysis. Well, in the test group for the left limb in all directions and in the control group for the right limb in two directions, the difference occurred between 3 or 2 and 1 test attempt. This may be evidenced by the fact that despite the use of test samples, preparing for the study and limiting the impact of science on the obtained values, the subsequent results after the first attempt are better than the previous ones. However, post-hoc analysis showed too few significant results to make a conclusion.

All dynamic balance results were normalized to limb length to be compared with other tests [27].

The above results without intervention (PRE-training stage) compared to the publication of Gorman et al. 2012, in which young

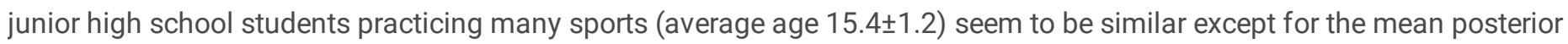
medial direction [33].

Referring to publications investigating the impact of interventions on dynamic balance, most researchers focused on neuromuscular training such as torso stabilization exercises and complex strength exercises such as squat. Filipa et al. 2012 showed significant improvement in the composite direction for the right and left limbs in young footballers after an 8-week program [34]. Imai et al. 2014 showed that a 12 week program of torso stabilization exercises has a positive effect on posterior lateral and posterior medial directions in footballers [35]. Both research groups used SEBT, they differed in intervention, study population and anthropometric characteristics.

One of the secondary goals of the study was to determine the risk of injury and reduce it by improving results. The risk reduction hypothesis was rejected.

Plisky et al. 2006 proved using SEBT that a composite score lower than $94 \%$ (normalized to limb length) caused a 6.5-fold higher risk of lower limb injury (95\% Cl: 2.4-7.5) in girls training basketball [36]. Butler et al. 2013 (September) examining 59 athletes practicing American football (average age 19.4 1 .1 years) showed that an athlete with a composite direction result in the $Y$ Balance Test below $89.6 \%$ was 3.5 times more exposed for injury [37]. Considering the conclusions from the above studies, despite the differences in the studied populations, one can risk the statement that the examined young footballers from this study have a low risk of injury due to dynamic balance.

The study was characterized by innovation due to the intervention undertaken. A selection of three exercises to strengthen specific muscles of the hip, knee and ankle joints. Exercises were selected based on available literature in terms of impact on a specific muscle [38-41].

Page $15 / 23$ 
This work is original in the context of assessing the intervention of young football players considered to have valgity knees. Nakagawa and Petersen, 2018 also used both SLS and YBT tests, but among healthy soldiers. They suggested strengthening the hips and increasing the range of motion of the ankles to improve the results of dynamic valgus [42].

Inverse correlation results between YBT and SLS showed statistically significant results mainly in the anterior direction with lower limb valgus and right control group. Also, an interesting fact is the extremely small inverse correlation for the intervention group. The inverse correlation of both tests may suggest a situation in which the participant who obtains a better result in dynamic equilibrium manifests itself in a smaller knee angulation angle. However, there are relatively few inverse correlations observed to the number of attempts, which makes it impossible to make a correct conclusion.

\section{Limitations}

This work should be considered in the light of many restrictions. There are restrictions on the use of 2D analysis to evaluate limb movement. First of all, low sensitivity in measuring changes in small angles. The results were not verified with the gold standard for evaluation of lower limb kinematics, which is 3D analysis. However, the angles of the extremities in the frontal projection in 2D are correlated with 3D results [43]. Kinematics assessment using Kinovea software used in this paper seems to be simpler to reproduce and without exposing costs in clinical settings. In addition, it requires no experience in video analysis and is easy to use to obtain accurate and reliable kinematic values of motion patterns [22].

Kinovea was used, among others, in studies concerning the analysis of height and time of the vertical jump, determination of knee and hip angles during running on the treadmill, sprint performance or evaluation of the lower limb in neurological patients after stroke [22,44-46]. In the assessment of squat kinematics this test is innovative.

The author used the test of valgus as an angle of knee displacement in the frontal plane $\geq 15^{\circ}$ from the starting position. In the available literature, most researchers used the criterion of knee displacement angle in the frontal plane $>0^{\circ}[32]$ or $>10^{\circ}[47]$.

Research Harris-Hayes 2014 showed that angle $>10^{\circ}$ is sufficient for proper visual assessment and classification as valgus [21].

The angle criterion proposed in this study was used to increase certainty as to the pattern classification and reduce the risk of error during video analysis.

In the context of other or further studies, this criterion may be described as "heavy" or "large" dynamic knee valgus.

The one-leg squat test requires proper neuromuscular control, stabilization and muscle strength in both the lower limbs and the torso.

Among participants aged 10-11 (year 2008), as many as 11 of 20 during the analysis were disqualified by loss of balance. This fact may suggest that the test may not be suitable for younger age groups.

Time to study interventions could be short in the context of increased muscle strength. The use of homework for young footballers in the studied age range raises a number of doubts about the correctness and actual implementation of the intervention program.

Further intervention studies could focus on given exercises, but with a longer program than 6 weeks, and focus on doing all the exercises correctly by running training units by a physiotherapist or trainer.

\section{Conclusions}

The 6-week program of strengthening the lower limb muscle of young school-age footballers with observed knee valgus has no beneficial effect on the dynamic balance and knee valgus values. The study showed that features such as leg length and limb dominance do not affect dynamic valgus. In addition, due to the Y-Balance test result of the composite direction, a low risk of injury in the studied population was established. 


\section{Abbreviations}

SLS: Single Leg Squat

YBT: Y-Balance Test

ANT: anterior

PL: posterolateral

PM: posteromedial

PRE: pre-training stage

POST: post-training stage

ANOVA: analysis of varianc

\section{Declarations}

\section{Ethics approval and consent to participate}

The study was approved by the Independent Bioethical Committee for Scientific Research at the Gdańsk Medical University (resolution NKBBN / 567/2018). The parents of each participating child received written information and signed a written parental consent to participate in the study. Participants and parents were informed that participation was voluntary, all collected information would be kept strictly confidential and only anonymized data would be published. They were free to ask questions about the research and could contact the researcher for questions by telephone.

\section{Consent for publication}

Not applicable.

\section{Availability of data and materials}

The datasets generated during and/or analysed during the current study are available from the corresponding author on reasonable request.

\section{Competing interests}

The authors declare that they have no competing interests.

\section{Funding}

This work was supported by the Medical University of Gdańsk [ST-02-0108/07/780].

The funders had no role in the study design, data collection, analysis, or interpretation/writing of the study.

\section{Authors' contributions}

Design of the study (KZ, BW); methodology (BW); statistical analysis (PW); analysis and interpretation of data (BW, PW, KZ); collection of data (BW); original draft preparation (BW); project administration (BW, KZ); review, editing and final approval (KZ). All authors read and approved the final manuscript.

\section{Acknowledgements}


Not applicable

\section{References}

[1] Krustrup P, Aagaard P, Nybo L, Petersen J, Mohr M, Bangsbo J. Recreational football as a health promoting activity: a topical review. Scand J Med Sci Sports. 2010;20 Suppl 1:1-13.

[2] Faude O, Rößler R, Junge A. Football injuries in children and adolescent players: are there clues for prevention? Sports Med. 2013;43:819-37.

[3] Giannotti M, Al-Sahab B, McFaull S, Tamim H. Epidemiology of acute soccer injuries in canadian children and youth. Pediatr Emerg Care. 2011;27:81-5.

[4] Adams AL, Schiff MA. Childhood soccer injuries treated in U.S. emergency departments. Acad Emerg Med. 2006;13:571-4.

[5] Read P, Oliver JL, Ste Croix MBA de, Myer GD, Lloyd RS. Injury Risk Factors in Male Youth Soccer Players. Strength and Conditioning Journal. 2015;37:1-7.

[6] Padua DA, Bell DR, Clark MA. Neuromuscular characteristics of individuals displaying excessive medial knee displacement. J Athl Train. 2012;47:525-36.

[7] Bell DR, Oates DC, Clark MA, Padua DA. Two- and 3-Dimensional Knee Valgus Are Reduced After an Exercise Intervention in Young Adults With Demonstrable Valgus During Squatting. J Athl Train. 2013;48:442-9.

[8] Bell DR, Padua DA, Clark MA. Muscle strength and flexibility characteristics of people displaying excessive medial knee displacement. Arch Phys Med Rehabil. 2008;89:1323-8.

[9] Ortqvist M, Moström EB, Roos EM, Lundell P, Janarv P-M, Werner S, Broström EW. Reliability and reference values of two clinical measurements of dynamic and static knee position in healthy children. Knee Surg Sports Traumatol Arthrosc.

2011;19:2060-6.

[10] Provencher MT, Higgins BT, Begly JP, Stone GL, Sanchez A, Murphy CP. Anterior Cruciate Ligament Prevention Programs Overview. In: ACL Injuries in Female Athletes: Elsevier; 2019. p. 13-23.

[11] Sheerin KR, Hume PA, Whatman C. Effects of a lower limb functional exercise programme aimed at minimising knee valgus angle on running kinematics in youth athletes. Phys Ther Sport. 2012;13:250-4.

[12] Herrington L, Munro A, Comfort P. A preliminary study into the effect of jumping-landing training and strength training on frontal plane projection angle. Man Ther. 2015;20:680-5.

[13] Mohammadi V, Hilfiker R, Jafarnezhadgero AA, Jamialahmadi S, Karimizadeh Ardakani M, Granacher U. Relationship between Training-Induced Changes in the Star Excursion Balance Test and the Y Balance Test in Young Male Athletes. Ann. Appl. Sport Sci. 2017;5:31-8.

[14] Palmer K, Hebron C, Williams JM. A randomised trial into the effect of an isolated hip abductor strengthening programme and a functional motor control programme on knee kinematics and hip muscle strength. BMC Musculoskelet Disord 2015.

[15] Dinc E, Kilinc BE, Bulat M, Erten YT, Bayraktar B. Effects of special exercise programs on functional movement screen scores and injury prevention in preprofessional young football players. J Exerc Rehabil. 2017;13:535-40.

[16] Faber M, Andersen MH, Sevel C, Thorborg K, Bandholm T, Rathleff M. The majority are not performing home-exercises correctly two weeks after their initial instruction-an assessor-blinded study. PeerJ 2015.

[17] Brewer BW, Cornelius AE, van Raalte JL, Tennen H, Armeli S. Predictors of Adherence to Home Rehabilitation Exercises Following Anterior Cruciate Ligament Reconstruction. Rehabil Psychol. 2013;58:64-72.

Page $18 / 23$ 
[18] Willson JD, Ireland ML, Davis I. Core strength and lower extremity alignment during single leg squats. Medicine \& Science in Sports \& Exercise. 2006;38:945-52.

[19] Gwynne CR, Curran SA. Quantifying frontal plane knee motion during single limb squats: reliability and validity of 2dimensional measures. Int J Sports Phys Ther. 2014;9:898-906.

[20] Kianifar R, Lee A, Raina S, Kulic D. Automated Assessment of Dynamic Knee Valgus and Risk of Knee Injury During the Single Leg Squat. IEEE J Transl Eng Health Med. 2017;5:2100213.

[21] Harris-Hayes M, Steger-May K, Koh C, Royer NK, Graci V, Salsich GB. Classification of Lower Extremity Movement Patterns Based on Visual Assessment: Reliability and Correlation With 2-Dimensional Video Analysis. J Athl Train. 2014;49:304-10.

[22] Balsalobre-Fernández C, Tejero-González CM, del Campo-Vecino J, Bavaresco N. The concurrent validity and reliability of a low-cost, high-speed camera-based method for measuring the flight time of vertical jumps. J Strength Cond Res. 2014;28:52833.

[23] Hébert-Losier K. Clinical Implications of Hand Position and Lower Limb Length Measurement Method on Y-Balance Test Scores and Interpretations. J Athl Train. 2017;52:910-7.

[24] Shaffer SW, Teyhen DS, Lorenson CL, Warren RL, Koreerat CM, Straseske CA, Childs JD. Y-balance test: a reliability study involving multiple raters. Mil Med. 2013;178:1264-70.

[25] Pomares-Noguera C, Ayala F, Robles-Palazón FJ, Alomoto-Burneo JF, López-Valenciano A, Elvira JLL, et al. Training Effects of the FIFA 11+ Kids on Physical Performance in Youth Football Players: A Randomized Control Trial. Front Pediatr 2018.

[26] Younis Aslan HI, Buddhadev HH, Suprak DN, San Juan JG. Acute effects of two hip flexor stretching techniques on knee joint position sense and balance. Int J Sports Phys Ther. 2018;13:846-59.

[27] Plisky PJ, Gorman PP, Butler RJ, Kiesel KB, Underwood FB, Elkins B. The Reliability of an Instrumented Device for Measuring Components of the Star Excursion Balance Test. N Am J Sports Phys Ther. 2009;4:92-9.

[28] Clark M.A., Lucett S.C., Sutton B.G., NASM Essentials of Corrective Exervise Training. Jones \& Bartlett Learning. 2014.

[29] R: A Language and Environment for Statistical Computing,R Core Team, R Foundation for Statistical Computing, Vienna, Austria, 2018, https://www.R-project.org/,

[30] Patrek MF, Kernozek TW, Willson JD, Wright GA, Doberstein ST. Hip-abductor fatigue and single-leg landing mechanics in women athletes. J Athl Train. 2011;46:31-42.

[31] Räisänen A, Pasanen K, Krosshaug T, Avela J, Perttunen J, Parkkari J. Single-Leg Squat as a Tool to Evaluate Young Athletes' Frontal Plane Knee Control. Clinical Journal of Sport Medicine. 2016;26.

[32] Räisänen AM, Pasanen K, Krosshaug T, Vasankari T, Kannus P, Heinonen A, et al. Association between frontal plane knee control and lower extremity injuries: a prospective study on young team sport athletes. BMJ Open Sport Exerc Med. 2018;4

[33] Gorman PP, Butler RJ, Rauh MJ, Kiesel K, Plisky PJ. Differences in dynamic balance scores in one sport versus multiple sport high school athletes. Int J Sports Phys Ther. 2012;7:148-53.

[34] Filipa A, Byrnes R, Paterno MV, Myer GD, Hewett TE. Neuromuscular Training Improves Performance on the Star Excursion Balance Test in Young Female Athletes. J Orthop Sports Phys Ther. 2010;40:551-8

[35] Imai A, Kaneoka K, Okubo Y, Shiraki H. Effects of two types of trunk exercises on balance and athletic performance in youth soccer players. Int J Sports Phys Ther. 2014;9:47-57. 
[36] Plisky PJ, Rauh MJ, Kaminski TW, Underwood FB. Star Excursion Balance Test as a predictor of lower extremity injury in high school basketball players. J Orthop Sports Phys Ther. 2006;36:911-9.

[37] Butler RJ, Lehr ME, Fink ML, Kiesel KB, Plisky PJ. Dynamic Balance Performance and Noncontact Lower Extremity Injury in College Football Players: An Initial Study. Sports Health. 2013;5:417-22.

[38] Nyland J, Lachman N, Kocabey Y, Brosky J, Altun R, Caborn D. Anatomy, function, and rehabilitation of the popliteus musculotendinous complex. J Orthop Sports Phys Ther. 2005;35:165-79.

[39] Kulig K, Burnfield JM, Requejo SM, Sperry M, Terk M. Selective Activation of Tibialis Posterior: Evaluation by Magnetic Resonance Imaging. Medicine \& Science in Sports \& Exercise. 2004:862-7.

[40] Reiman MP, Bolgla LA, Loudon JK. A literature review of studies evaluating gluteus maximus and gluteus medius activation during rehabilitation exercises. Physiotherapy Theory and Practice. 2012;28:257-68

[41] Soda N, Fujihashi Y, Aoki T. In vivo ultrasound imaging of the popliteus muscle: investigation of functional characteristics. J Phys Ther Sci. 2016;28:979-82

[42] Nakagawa TH, Petersen RS. Relationship of hip and ankle range of motion, trunk muscle endurance with knee valgus and dynamic balance in males. Phys Ther Sport. 2018;34:174-9.

[43] McLean S, Walker K, Ford K, Myer G, Hewett T, van den Bogert AJ. Evaluation of a two dimensional analysis method as a screening and evaluation tool for anterior cruciate ligament injury. Br J Sports Med. 2005;39:355-62

[44] Born D-P, Holmberg H-C, Goernert F, Sperlich B. A novel compression garment with adhesive silicone stripes improves repeated sprint performance - a multi-experimental approach on the underlying mechanisms. BMC Sports Sci Med Rehabil. 2014;6:21.

[45] Damsted C, Nielsen RO, Larsen LH. Reliability of video-based quantification of the knee- and hip angle at foot strike during running. Int J Sports Phys Ther. 2015;10:147-54.

[46] Dalal KK, Joshua AM, Nayak A, Mithra P, Misri Z, Unnikrishnan B. Effectiveness of prowling with proprioceptive training on knee hyperextension among stroke subjects using videographic observation- a randomised controlled trial. Gait Posture. 2018;61:232-7.

[47] Rees D, Younis A, MacRae S. Is there a correlation in frontal plane knee kinematics between running and performing a single leg squat in runners with patellofemoral pain syndrome and asymptomatic runners? Clin Biomech (Bristol, Avon). 2019;61:22732.

\section{Figures}




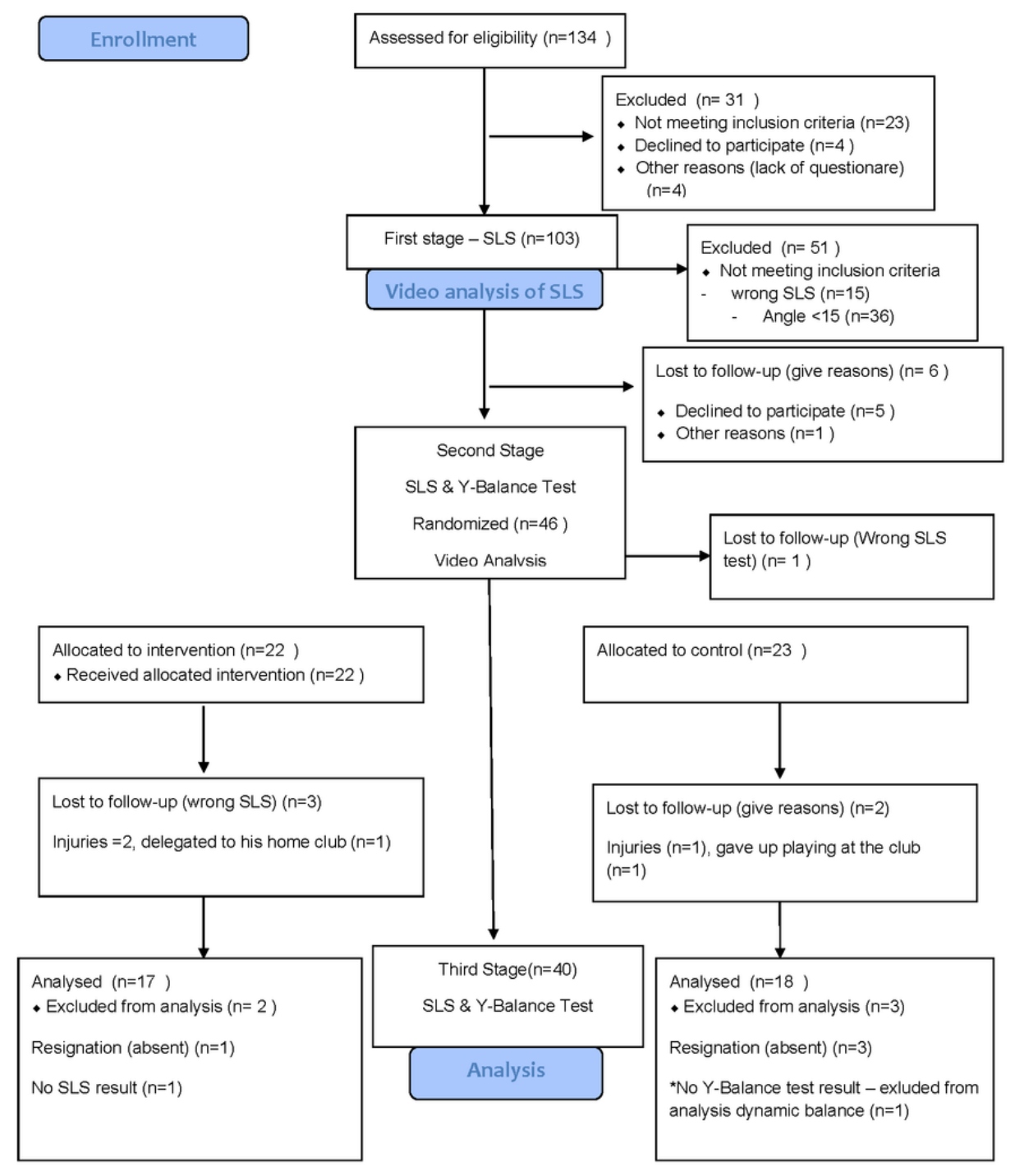

Figure 1

Participant flowchart 


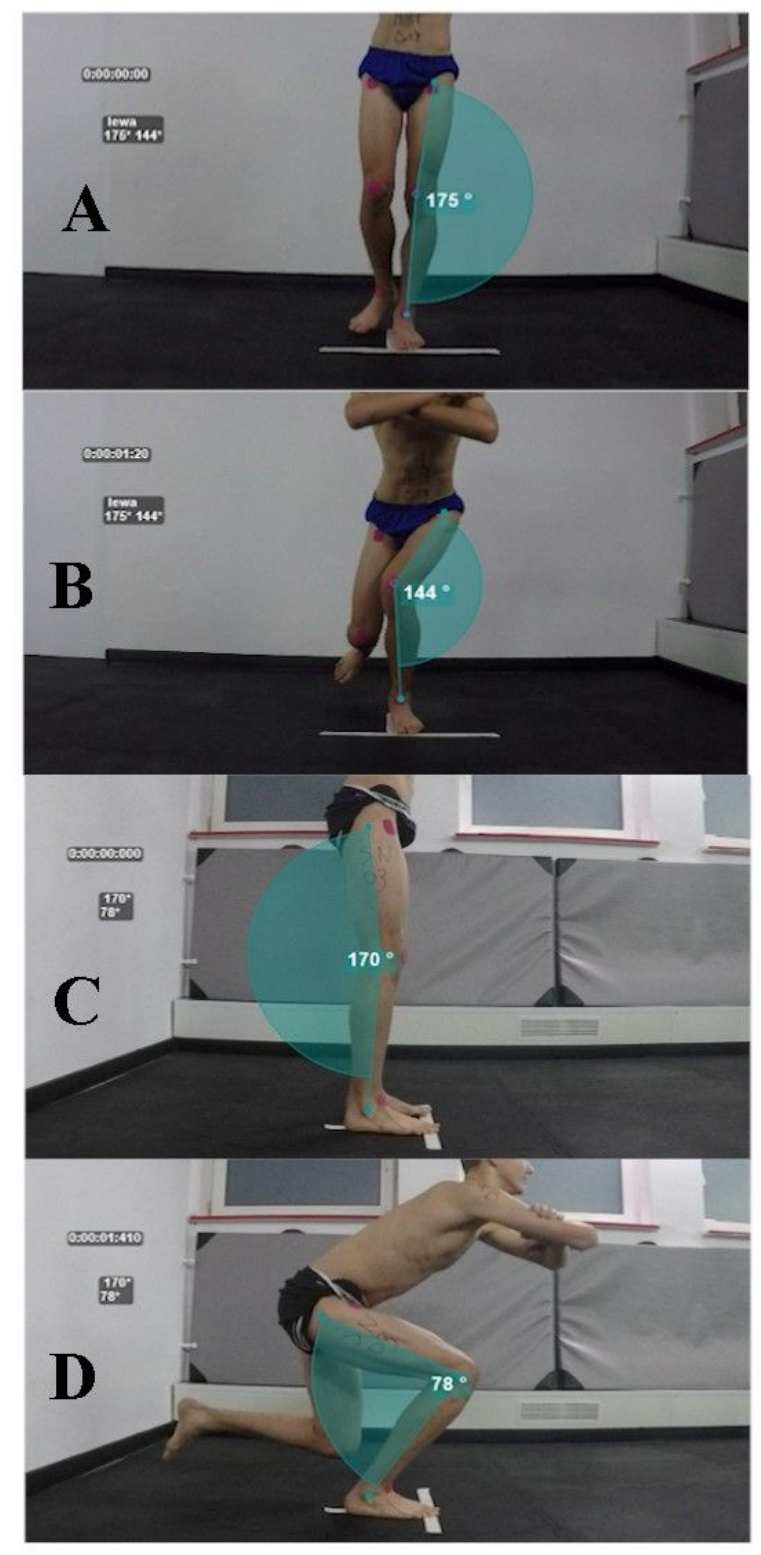

\section{Figure 2}

Video analyses of SLS Test in frontal and sagittal projection. Legend: (AB) - Frontal plane: A- starting position, B - end position (CD) - Sagittal plane: C - starting postition, D - end position

A

\section{Figure 3}

Exercises Legend: (AB) - exercise of gluteus medium (CD) - exercise of politeus (EF) - exercise of posterior tibalis 


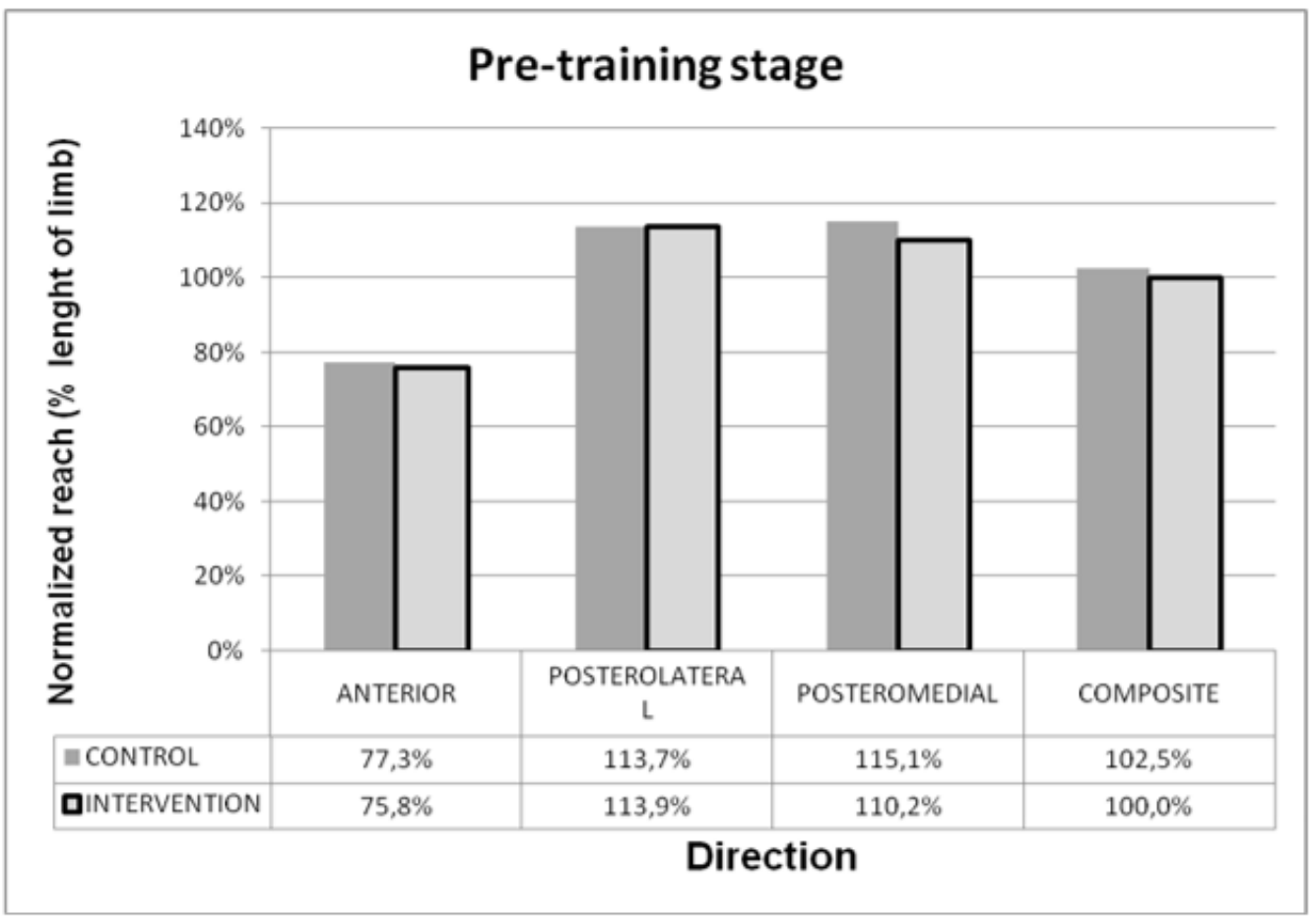

Figure 4

Comparison of control and intervention groups in all directions of the Y-Balance test in the pre training stage.

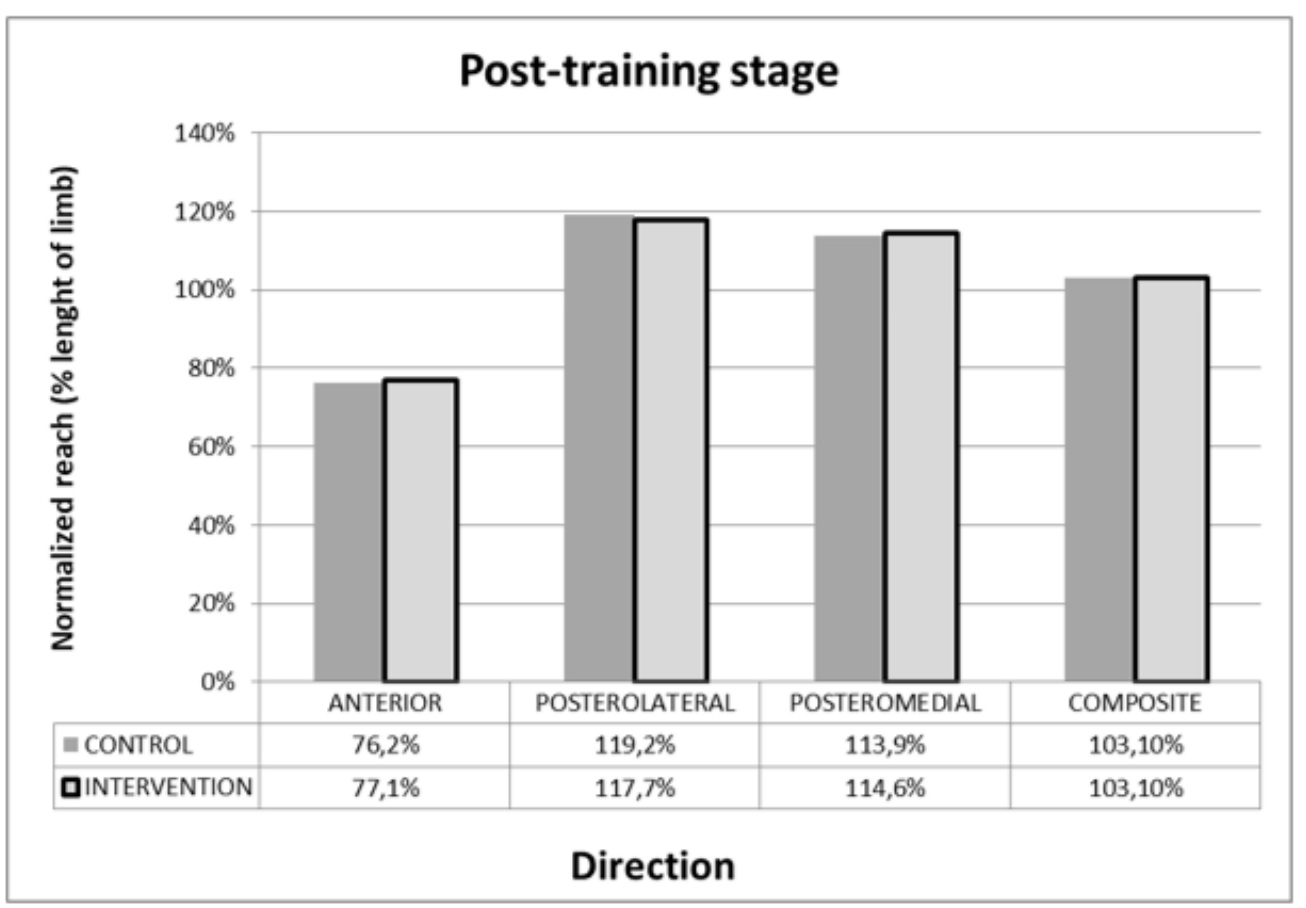

Figure 5

Comparison of control and intervention groups in all directions of the Y-Balance test in the post-training stage. 